\title{
Nationwide survey comparing residents' perceptions of overnight duty systems in Singapore: night float versus full overnight call
}

Benny Kai Guo LOQ ${ }^{1}$ MRCPCH, MMed, Chew Lip $\mathrm{Ng}^{2}$ MRCS, Lucy Jennifer Davies ${ }^{4}$, MBBS, MMed, Jin Yong ${ }^{5}$, MRCS, MMed, Andrea Ee Ling $\underline{\text { Ang }}^{6}$, MBBS, MRCP, Yeh Woei Chong ${ }^{7}$, MBBS, MRCP, Paul Ananth $\underline{\text { Tambyah }}^{8}$, MBBS, MD

\section{INTRODUCTION}

In 2010, the Accreditation Council for Graduate Medical Education International residency system was implemented in Singapore. This restricted the maximum working hours of residents to 80 hours per week. ${ }^{(1)}$ The traditional full overnight call (FOC) systems, whereby residents worked continuously for over 24 hours, have been implicated in contributing to fatigue, burnout and patient safety breaches. ${ }^{(2,3)}$ As a result, work restrictions have been introduced in Europe, North America and Australasia. ${ }^{(4)}$ Many Singapore teaching hospitals have since introduced the night float (NF) system, where residents are allowed to work 12- to 14-hour night shifts for 5-7 consecutive nights instead of doing an FOC. Residents on NF do not perform daytime duties. This allows them to have about 12 hours of rest in between their overnight duties.

Theoretically, NF systems are said to decrease fatigue, burnout and medical errors. ${ }^{(5,6)}$ However, the evidence supporting this optimistic assessment of the NF system is equivocal. Reported disadvantages include decreased learning opportunities, patient safety issues attributed to frequent handovers, and no evidence of better quantity of sleep according to studies in Singapore. ${ }^{(6,7)}$ Both the NF and FOC systems are concurrently being implemented in different departments and services across many Singapore hospitals, depending on manpower and service needs. We believe that when comparing the two call systems, it would be useful to understand the perceptions of residents about the impact of these call systems on patient safety, clinical training and physician burnout. Thus, we conducted a questionnaire-based study to assess and analyse the perceptions of residents towards the NF and FOC systems.

\section{METHODS}

The Singapore Medical Association (SMA), with permission from the Graduate Medical Education (GME) Offices of all three sponsoring institutions (SIs) in Singapore - Singapore Health Services, National University Health System and National Healthcare Group - conducted a questionnaire-based survey to examine residents' views of the NF system compared with the FOC system in relation to patient safety, clinical training and physician burnout. Sls are groups of hospitals that offer the various residency training programmes. The survey was based on a previous questionnaire developed by residents and the faculty for the study of first-year postgraduate doctors' perceptions of the $\mathrm{NF}$ and FOC systems in a local internal medicine programme. ${ }^{(8)}$

The survey was conducted using the online survey application SurveyMonkey® and comprised of 17 questions that covered the following domains: demographic information; patient safety and medical errors; clinical work and training; and physician burnout and hospital choice (Box 1). All questions required a single-choice response, either a 'Yes' or ' $\mathrm{No}^{\prime}$ answer for an incidence-type question, or rating using a 5-point Likert scale for rating-type questions. For questions involving the 5-point Likert scale, a score $\geq 4$ was considered a positive response.

An invitation email to participate in the survey was sent through the GME Offices to all residents in the three SIs on 29 March 2019. The survey concluded four weeks later on 30 April 2019. It was stated clearly in the introduction to the survey that participation was voluntary, all responses were anonymous, and the identities of respondents and non-respondents were not collected. As this study was categorised as a service evaluation and did not involve collation of participant data, institutional review board approval was not required.

\section{RESULTS}

There were a total of 636 complete responses, of which 400 $(62.9 \%)$ respondents had worked in both FOC and NF systems. The levels of training of the respondents at the time of response are presented in Table I.

Survey results are presented in Table II. On perceptions of patient safety, $86.9 \%$ agreed/strongly agreed that NF may help to prevent medical errors, while $7.1 \%$ felt that FOC may help prevent medical errors. A majority of $74.7 \%$ expressed that they had made a medical error on the FOC system, as compared to $14.9 \%$ on the NF system.

On residents' perceptions of learning, $78.9 \%$ of respondents agreed/strongly agreed that the NF system was less disruptive to

\footnotetext{
${ }^{1}$ Department of Paediatric Medicine, KK Women's and Children's Hospital, ${ }^{2}$ Department of Ear, Nose \& Throat - Head \& Neck Surgery, Ng Teng Fong General Hospital, ${ }^{3}$ Department of Endocrine, National University Hospital, ${ }^{4}$ Department of Anaesthesia, ${ }^{5}$ Department of Urology, Singapore General Hospital, ${ }^{6}$ Department of Rheumatology, Tan Tock Seng Hospital, ${ }^{7}$ Singapore Medical Specialists Centre, ${ }^{8}$ Department of Infectious Diseases, National University Hospital, Singapore

Correspondence: Dr Benny Loo Kai Guo, Consultant, Department of Paediatric Medicine, KK Women's and Children's Hospital, 100 Bukit Timah Road, Singapore 229899. benny.loo.k.g@singhealth.com.sg
} 
Box 1. The 17-question survey of residents' views on night float call and full overnight call systems comprised four domains:

\section{Demographic information}

1. What's your current appointment?

2. Have you experienced the night float call system and the full overnight call system in any posting?

\section{Patient safety and medical errors}

3. Does night float call system contribute to patient safety?

4. Does full overnight call system contribute to patient safety?

5. Does night float call system help to reduce medical errors?

6. Does full overnight call system help to reduce medical errors?

7. Have you made mistakes at work after being on the night float call system?

8. Have you made mistakes at work after being on the full overnight call system?

\section{Clinical work and training}

9. Is night float call system less disruptive to daily clinical work as compared to full overnight call system?

10. Does night float call system build teamwork and camaraderie?

11. Does night float call system make junior doctors less competent due to shorter working hours?

12. Does full overnight call system make junior doctors more competent due to longer working hours?

\section{Physician burnout and hospital choice}

13. Does night float call system help to reduce burnout for junior doctors?

14. Do you feel alert and able to think rationally for patient management during night float call duty?

15. Do you feel safe to carry out your duties after full overnight call duty?

16. Does having night float system influence your preferred choice of hospital to work in?

17. Would you prefer your family member to be cared for by a doctor on night float call as opposed to full overnight call duty?

Table I. Number and levels of training of respondents.

\begin{tabular}{|lll|}
\hline \multirow{2}{*}{ Level of training } & \multicolumn{2}{c|}{ No. (\%) } \\
\cline { 2 - 3 } & $\begin{array}{l}\text { Total } \\
(\mathbf{n}=\mathbf{6 3 6})\end{array}$ & $\begin{array}{l}\text { Worked in both } \\
\text { systems ( } \mathbf{n = 4 0 0 )}\end{array}$ \\
\hline Junior resident (PGY 1) & $154(24.2)$ & $50(12.5)$ \\
\hline Junior resident (PGY 2 and above) & $340(53.5)$ & $247(61.8)$ \\
\hline Senior resident & $142(22.3)$ & $103(25.8)$ \\
\hline
\end{tabular}

PGY: postgraduate year

daily clinical work, and $70.9 \%$ of respondents also agreed/strongly agreed that NF helped in building teamwork and camaraderie. $85.7 \%$ of respondents disagreed/strongly disagreed that the FOC, with longer working hours, would produce more competent doctors, and $89.1 \%$ of respondents disagreed that the NF system, with its shorter work hours, would produce less competent doctors.

The NF system was perceived to have a beneficial effect on physician burnout and impacts residents' choice of hospital for work or medical care. $84.4 \%$ agreed/strongly agreed that NF helped to reduce burnout. On perceptions of ability to function during or after night duty, $91.3 \%$ responded that they felt alert when working on NF duty, and $72.2 \%$ felt unsafe to perform clinical duties after FOC duty. This is relevant because residents are usually required to continue with clinical work for up to six hours after completing an FOC shift. For $70.0 \%$ of respondents, having an NF system would influence their choice of hospital to work in. $82.2 \%$ of respondents would prefer to have their family members cared for in hospitals with NF systems.

\section{DISCUSSION}

There are proponents and opponents for both on-call systems, and studies have been conducted to measure and assess their advantages and disadvantages. ${ }^{(5-7)}$ We believe that understanding the perceptions and preferences of residents, for whom the call systems are designed, has great value in improving both of the existing call systems. With this objective in mind, we designed a questionnaire-based study, which is to our knowledge the first nationwide survey of residents' opinions of on-call systems in Singapore. As the majority (62.9\%) of respondents had experienced both call systems, and three-quarters of respondents had spent more than one year in the local postgraduate training system, they were able to assess the relative strengths and weaknesses of both.

Similar to other studies, almost $90 \%$ of residents perceived that the NF system contributed to patient safety and might lead to fewer medical errors as compared to the FOC system. ${ }^{(6)}$ In this study, five times more residents reported that they had made medical errors while working in the FOC system than in the NF system $(74.7 \%$ vs. $14.9 \%)$. This could be due to shorter working hours and longer rest periods, leading to greater alertness and also better continuity of patient care. ${ }^{(9)}$ While this result was based on self-reporting of errors, we opine that the significant difference in perception provides a valuable insight into residents' opinions on how they perceive the two systems in the context of patient safety. Notably, this finding remains as self-reported data, and subsequent studies are warranted to corroborate this finding with objective data from adverse event reporting systems. Although adverse event reporting systems are objective, a limitation of relying on them is that not all medical errors result in significant adverse events or patient harm and thus may not be captured.

More than $70 \%$ of respondents perceived that the NF system was less disruptive to their daily clinical work and helped to inculcate teamwork. We postulate that this could be due to having the same team of doctors working together for many consecutive nights in the NF system. A study has shown that consistency of care could improve cooperation among team members and translate to better continuity of patient care and better patient-doctor rapport. ${ }^{(10)}$ Connelly et al similarly reported that medical students perceived an enhanced level of teamwork after a week of NF. ${ }^{(11)}$

One traditional method of measuring level of training is to look at the number of hours of clinical work performed, with the common assumption that longer work hours translate into proficiency. However, it has been shown that prolonged working hours may lead to increased fatigue and attention failure, which could compromise learning and patient care. This was supported by our survey, where $85.7 \%$ of the respondents did not agree that longer overnight call hours helped in improving their competency. On the other hand, residents also expressed that during a busy FOC, it was not uncommon to have a 'survival-mode' 
Table II. Survey results from 636 respondents from all three sponsoring institutions.

\begin{tabular}{|c|c|c|c|}
\hline \multirow[t]{2}{*}{ Question } & \multicolumn{3}{|c|}{$\%$} \\
\hline & $\begin{array}{l}\text { Disagree } \\
\text { or strongly } \\
\text { disagree/no }\end{array}$ & Neutral & $\begin{array}{l}\text { Agree or } \\
\text { strongly } \\
\text { agree/yes }\end{array}$ \\
\hline Does night float call system contribute to patient safety? & 3.0 & 7.4 & 89.6 \\
\hline Does full overnight call system contribute to patient safety? & 78.0 & 14.9 & 7.1 \\
\hline Does night float call system help to reduce medical errors? & 3.0 & 10.1 & 86.9 \\
\hline Does full overnight call system help to reduce medical errors? & 84.0 & 12.1 & 3.9 \\
\hline Have you made mistakes at work after being on the night float call system?* & 85.1 & - & 14.9 \\
\hline Have you made mistakes at work after being on the full overnight call system?* & 25.3 & - & 74.7 \\
\hline $\begin{array}{l}\text { Is night float call system less disruptive to daily clinical work as compared to } \\
\text { full overnight call system? }\end{array}$ & 7.2 & 13.9 & 78.9 \\
\hline Does night float call system build teamwork and camaraderie? & 7.1 & 22.0 & 70.9 \\
\hline $\begin{array}{l}\text { Does night float call system make junior doctors less competent due to shorter } \\
\text { working hours? }\end{array}$ & 89.1 & 7.4 & 3.5 \\
\hline $\begin{array}{l}\text { Does full overnight call system make junior doctors more competent due to } \\
\text { longer working hours? }\end{array}$ & 85.7 & 8.5 & 5.8 \\
\hline Does night float call system help to reduce burnout for junior doctors? & 3.8 & 11.8 & 84.4 \\
\hline $\begin{array}{l}\text { Does having night float system influence your preferred choice of hospital to } \\
\text { work in? }\end{array}$ & 8.5 & 21.5 & 70.0 \\
\hline $\begin{array}{l}\text { Would you prefer your family member to be cared for by a doctor on night } \\
\text { float call as opposed to full overnight call duty? }\end{array}$ & 4.9 & 14.9 & 82.2 \\
\hline
\end{tabular}

*These questions required a 'Yes' or 'No' response.

mentality, where the primary objective was to seek rest, instead of increasing their learning. ${ }^{(12)}$ The challenge is then to balance work requirements and clinical training at night, and evaluate the quality of learning with objective workplace assessments. A novel, resident-led curriculum by Brady et al showed that it was possible to conduct regular structured teaching at night. ${ }^{(13)}$ This could be incorporated into local call systems as well.

Junior doctors, especially those in Postgraduate Year 1, are more susceptible to burnout. ${ }^{(14)}$ Duty hour restrictions were implemented to reduce physician burnout and to improve physician well-being. ${ }^{(15,16)} 84.4 \%$ of respondents agreed that NF helped to reduce burnout. This could be due to a combination of shorter working hours or longer rest periods, as compared to FOC. The stable team structure and familiar work environment may also contribute to improved emotional and mental health, although this hypothesis requires verification with future studies.

In the present study, respondents were asked if the availability of an NF system in a hospital would affect their subsequent choice of employment and the choice of hospital for their loved ones. The former question was centred on the respondents' personal welfare, but the latter compelled the respondents to picture their loved ones requiring care in a hospital, shifting their focus from their personal welfare to that of a loved one, incorporating emotive elements into their response. $70.0 \%$ agreed that having an NF system in a hospital would influence their choice of place of employment, and more tellingly, $82.2 \%$ preferred residents on an NF system to care for their loved ones. We see this as an acid test of the residents' preference for and confidence in the NF system.

Implementing an NF system is not without its challenges. Firstly, it requires more manpower than the FOC system, rendering it less feasible in smaller institutions or departments. Secondly, the NF system is probably more relevant to specialties with a significant acute inpatient load and has a limited role in services with a high elective or outpatient load. Thirdly, consultant supervision may be limited with the NF system, as most consultants may not be physically present in the hospital during an NF shift; opportunities for feedback may thus be limited. A study by Sadowski et al showed that patient safety was enhanced in an NF system when a list of clinical events that necessitated escalation to the consultant was adopted. ${ }^{(17)}$ Defilippis et al separately described a viable on-site attending physician model that improved resident education and quality of patient care. ${ }^{(18)}$

There were limitations to this study. The identities of respondents were not verified, hence any person with access to the email invitation could fill in the questionnaire. We mitigated this risk by distributing the survey through the GME Offices. In addition, there could be selection bias in the survey, whereby residents who were in favour of the NF system were more likely to respond. The study was also subject to recall bias in view of its cross-sectional nature. However, as this is the largest survey of Singapore residents to date, to the best of our knowledge, the perceptions of local residents are likely to be well represented. We are aware of the limitations of a study that is subjective and perception-based, and do not seek to establish the superiority of one system over another. Nevertheless, we believe that our assessment and analysis of the perceptions of residents who serve in the call systems is of value to healthcare leaders and educators, and may stimulate further studies on this intriguing topic.

In conclusion, this nationwide survey of residents demonstrated that a majority of residents perceived the NF system more 
favourably vis-a-vis the FOC system in the domains of patient safety and medical errors, clinical work and training, physician burnout and hospital choice. We hope our findings will help shed light on the opinion, preferences and concerns of residents towards on-call systems, for the consideration of educators, academics and healthcare leaders who implement such systems.

\section{ACKNOWLEDGEMENTS}

The authors would like to thank the GME Offices of the three SIs for disseminating the questionnaire. We would also like to thank Ms Mellissa Ang and Ms Ashley Soh from the SMA Secretariat for their administrative help in this project.

\section{REFERENCES}

1. Singapore Medical Council. SMC Circular. Guidelines on Postgraduate Year 1 (PGY1) training and postings for the accreditation of PGY1 training posts. 20 October 2017.

2. Barger LK, Ayas NT, Cade BE, et al. Impact of extended-duration shifts on medical errors, adverse events, and attentional failures. PLoS Med 2006; 3:e487.

3. Scarella TM, Nelligan J, Roberts J, Boland RJ. Effect of call organization on burnout and quality of life in psychiatry residents. Asian J Psychiatr 2017; 25:27-30.

4. Temple J. Resident duty hours around the globe: where are we now? BMC Med Educ 2014; 14(Suppl 1):S8.

5. Sterling L, McCaffrey C, Secter M, et al. Development of a night float call model for obstetrics and gynaecology residency: the process and residents' perceptions. J Obstet Gynaecol Can 2016; 38:1061-4.e1.

6. Sun NZ, Gan R, Snell L, Dolmans D. Use of a night float system to comply with resident duty hours restrictions: perceptions of workplace changes and their effects on professionalism. Acad Med 2016; 91:401-8.

7. Low JM, Tan MY, See KC, Aw MM. Sleep, activity and fatigue reported by postgraduate year 1 residents: a prospective cohort study comparing the effects of night float versus the traditional overnight on-call system. Singapore Med J 2018; 59:652-5.

8. Tan BY, Ngiam NJ, Chang ZY, et al. Perceptions of a night float system for intern doctors in an internal medicine program: an Asian perspective. Korean J Med Educ 2019; 31:271-6.

9. Lafleur A, Harvey A, Simard C. Adjusting to duty hour reforms: residents'perception of the safety climate in interdisciplinary night-float rotations. Can Med Educ J 2018; 9:e111-9.

10. Davis MC, Kuhn EN, Agee BS, Oster RA, Markert JM. Implications of transitioning to a resident night float system in neurosurgery: mortality, length of stay, and resident experience. J Neurosurg 2017; 126:1269-77.

11. Connelly CR, Bohan PM, Cook MR, et al. A night float week in a surgical clerkship improves student team cohesion. Am J Surg 2016; 211:913-8.

12. Passalacqua SA, Segrin C. The effect of resident physician stress, burnout, and empathy on patient-centered communication during the long-call shift. Health Commun 2012; 27:449-56.

13. Brady AK, O'Rourke P, Kobayashi T, et al. A novel, resident-led curriculum for night float rotations. J Grad Med Educ 2015; 7:289-90.

14. Tan MY, Low JM, See KC, Aw MM. Comparison of sleep, fatigue and burnout in post-graduate year 1 (PGY1) residents and faculty members--a prospective cohort study. Asia Pacific Scholar 2017 May 2. https://doi.org/10.29060/ TAPS.2017-2-2/OA1012.

15. Reed DA, Fletcher KE, Arora VM. Systematic review: association of shift length, protected sleep time, and night float with patient care, residents' health, and education. Ann Intern Med 2010; 153:829-42.

16. Veasey S, Rosen R, Barzansky B, Rosen I, Owens J. Sleep loss and fatigue in residency training: a reappraisal. JAMA 2002; 288:1116-24.

17. Sadowski BW, Medina HA, Hartzell JD, Shimeall WT. Nighthawk: making night float education and patient safety soar. J Grad Med Educ 2017; 9:755-8.

18. Defilippis AP, Tellez I, Winawer N, et al. On-site night float by attending physicians: a model to improve resident education and patient care. J Grad Med Educ 2010; 2:57-61. 